\title{
The Patient Medication List: Can We Get Patients More Involved in Their Medical Care?
}

\author{
Sung Y. Chae, MD, Mark H. Chae, PhD, Nicole Isaacson, PhD, LSW, and \\ Tarika S. James, $M D$
}

Background: Patient involvement is essential to maintain accurate and updated medication lists, provide quality care, and decrease potential errors. The purpose of this study was to determine the acceptance of medication lists maintained by patients and if their use affected perceptions of patient and physician responsibility and patients' knowledge of their medical care.

Methods: A foldable, wallet-sized medication list card was distributed to a convenience sample of 104 patients $\geq 40$ years of age at an outpatient residency site. They were also given a survey of demographic variables and the Patient Medication Scale, which measures their perceptions of patient responsibility, physician responsibility, and patients' knowledge of their medical care. They were contacted by phone 4 to 11 months later to ascertain if they were using the medication card and the Patient Medication Scale was readministered.

Results: Forty-two of 66 patients contacted after the intervention consented to a full interview. Thirty-eight percent ( 25 of 66 ) reported using the card. The patients using the card showed increased scores in perceived patient knowledge and patient responsibility, with no change in their perceptions of physician responsibility. Among the 41 respondents not using the card, approximately half indicated interest in using the card in the future or were using a card of their own.

Conclusions: A significant percentage of patients were willing to use the medication list card. Use of the card also seemed to increase their sense of responsibility and perceived knowledge of their medical care. (J Am Board Fam Med 2009;22:677-685.)

The prevention of medication errors is a leading goal among health care organizations in the pursuit of providing quality medical care. The Joint Commission had prioritized medication reconciliation among its 2008 National Patient Safety Goals. ${ }^{1}$ Embedded within the goal of medication reconciliation was the recommendation to "provide the patient with a medication card that includes the list of all the medications he/she is taking and encourage timely updating of the list. The patient should be encouraged to carry the card in his/her wallet or

This article was externally peer reviewed.

Submitted 24 March 2009; revised 13 June 2009; accepted 22 June 2009.

From the JFK Family Medicine Residency Program, Edison, NJ (SYC); the Department of Psychiatric Rehabilitation \& Counseling Professions, University of Medicine \& Dentistry of New Jersey, Newark (MHC); Counseling and Psychological Services, Rutgers-The State University of New Jersey, New Brunswick (NI); and Adult Medicine Department, Brownsville Multiservice Family Health Center, Brooklyn, NY (TSJ)

Funding: none.

Conflict of interest: none declared.

Corresponding author: Sung Y. Chae, MD, JFK Family Medicine Residency Program, 65 James Street, Edison, NJ 08818-3059 (E-mail: schae@solarishs.org). purse." Although examples of patient medication lists abound, there is a dearth of research about patient acceptance and actual use of these medication list cards. The literature review undertaken for this project revealed little empirical data on this subject.

Research in both the inpatient and outpatient settings has consistently indicated a significant rate of discrepancies in documented patient medication lists, with the potential for adverse effects and drug interactions. The percentage of charts with discrepancies in medication lists has ranged between $48 \%$ to $98.2 \%$ across these studies. ${ }^{3-12}$ Given the fragmentation of the current health care system, with patients seeing multiple healthcare providers who may not know what medications are being prescribed by others, it would be helpful to have an integrated medical information system. ${ }^{13}$ The use of electronic health records and other similar technologies has been hailed for their potential to decrease errors and improve patient care. ${ }^{14}$ However, research indicates that the mere implementation of a paperless system is insufficient to eradicate discrepancies in medication lists ${ }^{11,15}$ or prescribing errors. ${ }^{16}$ 
Patients also take many over-the-counter and herbal remedies, which their healthcare providers may not know about. ${ }^{17,18}$ Therefore, any approach to maintaining a complete medication list will need to involve the patient and/or their families. There is much excitement about the potential role of electronic personal health records in helping to achieve this goal. ${ }^{19}$ Multiple private organizations have entered this market, including Google and Microsoft as well as insurance companies like Aetna and Blue Cross Blue Shield. The Center for Medicare and Medicaid Services is also pilot testing web-based personal health records. ${ }^{20}$ However, there are real concerns about the confidentiality and interoperability of these records because of the lack of standardization across the multiple products available. In addition, the limited health literacy of the American population ${ }^{2,21-23}$ and the lack of Internet access for those with limited resources narrow the availability of this resource to many patients.

Although multiple studies document discrepancies between office and hospital medication records and those medications that the patients actually report taking during in-depth interviews and/or contact with pharmacies, ${ }^{3-12,15}$ few studies have examined the involvement of patients in actively updating their medication lists. Bedell et $\mathrm{al}^{7}$ conducted a study in a group internal medicine practice where patients were instructed to bring in a "brown bag" of all the medications they were taking (both prescription and over the counter) to the next office visit. This study identified discrepancies in the charts of $76 \%$ of the 312 patients that were examined compared with the actual medications they brought in.

Another study of 50 outpatients in geriatric clinics ${ }^{8}$ compared the medication lists generated by routine office interviews with the "brown bag" of medications and compared these lists to those generated by a room-to-room search of the patients' homes in conjunction with a semistructured interview. Among these 50 patients, 23 (48\%) had omissions of at least one medication and $9(19 \%)$ had at least one omission of a regular prescription medication. This study indicated that even the "brown bag" method was not flawless and could still lead to significant discrepancies.

A pilot study at the preventive medicine department of the Mayo Clinic $^{11}$ examined the use of a combined intervention involving providers and pa- tients. The patients were sent a letter encouraging them to list all of their current medications as well as any over-the-counter and herbal remedies and to bring this list to their next visit (and/or the "brown bag" of these medications). The providers were trained in techniques of medication reconciliation. This combined approach improved the documentation of patient-reported medications from $47.3 \%$ to $92.6 \%$.

Nassaralla et $\mathrm{al}^{15}$ examined a multifaceted approach to medication reconciliation in an outpatient internal medicine clinic involving every member of the health care team. The secretary reminded the patients to bring in an updated medication list or a "brown bag" of their medications. When the patient arrived, the receptionist gave the patient a medication list to complete if they did not bring one of their own. A licensed practical nurse (who had been trained in documenting medications) then recorded this list in the electronic record, which the physician then reviewed with the patient and updated. Finally, the transcriptionist was instructed to contact the physician if there were any discrepancies between the physician's dictation and the medication list in the note. This list was then compared with the list generated by the patient during a phone interview. This intervention improved the completeness of medication lists from $7.7 \%$ (before the intervention) to $17 \%$ (after the intervention). However, one of the challenges noted in this study was that the majority of the patients did not actively participate by bringing the requested updated medication list or the "brown bag" of medications to the office visit.

Given the critical nature of patient involvement in the process of keeping updated, accurate medication lists, the purpose of this study was 2 -fold. The first was to determine whether patients would accept the charge to use a wallet-sized medication list. The second was to ascertain if doing so affected the perceptions of their knowledge about their medications and medical problems, as well as their responsibility to help maintain their records and their perceptions of the corresponding responsibility of their physicians in maintaining this information.

\section{Methods}

A wallet-sized, foldable medication list card was distributed to a convenience sample of 104 patients 
$\geq 40$ years old at an outpatient family medicine residency practice during a 3 -month period in 2006. The study site was a multiethnic residency practice that handles more than 26,000 patient visits annually. Consent to participate in this study was obtained from each patient or his/her caregiver. Nurses approached patients to participate and instructed them to regularly update the list with current medications, including over-thecounter medications and herbal remedies. The patients also filled out an initial survey of demographic variables and the Patient Medication Scale (PMS).

The PMS is a 9-item scale that assesses 3 domains, including perceived patient responsibility, physician responsibility, and patients' knowledge of their medical care (see Appendix 1). The scale was developed for this study because the review of literature did not locate an instrument that would assess these domains of patient perceptions of their medical care through the use of a medication card. The items of the PMS were developed based on the extant medical literature and feedback from primary care physicians and faculty of family medicine training programs. Further assistance was obtained from a focus group at the Research Division of the Department of Family Medicine at the University of Medicine and Dentistry of New Jersey, Robert Wood Johnson School of Medicine.

The patients who agreed to continued participation in this study underwent a scripted phone interview with one of 2 investigators (SC and TJ) (see Appendix 2) 4 to 11 months later to determine whether they were using the card; the PMS was readministered at this time. The responses to the PMS before and after the intervention were assessed, with the use of the card entered as the independent variable in a paired samples $t$ test and multivariate analysis of variance using SPSS software (version 16.0, SPSS, Inc., Chicago, IL) (tests done by MC). Qualitative responses were also reviewed according to the grounded theory approach where themes emerged during the course of the data analysis. ${ }^{24}$ Institutional Review Board approval was obtained for this study.

\section{Results}

Because there was no previous study focused specifically on the questions of this project, the PMS was developed and analyzed with the 99 full re-
Table 1. Demographics of the Participants at the Study Onset* and at Phone Follow-up 4 to 11 Months Later ${ }^{\dagger}$

\begin{tabular}{lcc}
\hline & $\begin{array}{c}\text { Before Intervention } \\
(\mathrm{n}=99)\end{array}$ & $\begin{array}{c}\text { After Intervention } \\
(\mathrm{n}=42)\end{array}$ \\
\hline $\begin{array}{l}\text { Age (mean [SD]) } \\
\text { Gender (n [\%]) }\end{array}$ & $60.36(13.42)$ & $60.38(12.07)$ \\
Male & $34(34.3)$ & $13(31.0)$ \\
Female & $65(65.7)$ & $29(69.0)$ \\
Race (n [\%]) & & \\
White & $60(60.6)$ & $27(64.3)$ \\
African & $21(21.2)$ & $10(23.8)$ \\
American & $11(11.1)$ & $4(9.5)$ \\
Asian & $4(4.0)$ & $1(2.4)$ \\
Latino & $2(2.0)$ & - \\
Other & & \\
\hline
\end{tabular}

*Before intervention, when the medication list card was distributed.

${ }^{\dagger}$ After intervention.

${ }^{{ }} \mathrm{n}=98$ before intervention (1 unanswered).

sponses before the intervention. Of the 104 patients who initially consented to participate in the study, 5 were excluded because they filled out less than half of the PMS. Cronbach's $\alpha$, assessed for the entire scale, rendered a coefficient of 0.70 . The 3 domains included patient knowledge $(\alpha=0.65)$, patient responsibility $(\alpha=0.73)$, and physician responsibility $(\alpha=0.80)$.

We were subsequently able to contact 66 of these 99 patients by phone. Forty-two agreed to complete the full questionnaire after intervention. Twenty-five of the 66 patients (38\%) expressed that they were using the medication list card. Fiftytwo of the entire 99 patients $(52.5 \%)$ indicated that they were getting prescriptions from more than one health care provider.

The demographic variables of age, sex, and race are outlined on Table 1 . Of note, although only 42 out of the initial 99 patients completed the full follow-up questionnaire, analysis of the mean age by $t$ test and the sex and racial distributions by $\chi^{2}$ tests showed no statistically significant difference between these 2 groups.

A paired samples $t$ test, with the use of the medication list card entered as the independent variable, showed that those who used the card scored higher on the dependent variables of perceived patient responsibility $(P=.031)$ and patient knowledge $(P=.049)$ domains of the PMS ( $\mathrm{n}=$ $42)$. However, there was no significant difference in the perceived physician responsibility domain $(P=$ 


\begin{tabular}{|c|c|}
\hline Personal Reference & $\begin{array}{l}\text { - When I look at it, it guides me what medications I have to continue taking. } \\
\text { Reference when order medicine from Pathmark. } \\
\text { - Told me what I was on because I don't remember all the time the } \\
\text { medications I am on. }\end{array}$ \\
\hline Physician Reference & $\begin{array}{l}\text { - Excellent. Useful at doctor's office. When I went to doctor's office and I } \\
\text { didn't have everything on file [it was useful]. Easier for doctor to know, to } \\
\text { update. } \\
\text { - When I go to doctors and when they ask me my medications and I need to } \\
\text { clarify [I can use the card]. }\end{array}$ \\
\hline Reference Across Healthcare Settings & $\begin{array}{l}\text { - Helpful. When I go to doctor and they check my medications I can hand it } \\
\text { over to them. It makes it easy for the doctor. Anytime going to doctor; } \\
\text { foot doctor, heart specialist, another doctor. Easy to put in my wallet. } \\
\text { - It is very helpful. I take it with me to doctors' appointments and to } \\
\text { [emergency room]. } \\
\text { - Also useful when filling out Plan D information. }\end{array}$ \\
\hline Family Reference & $\begin{array}{l}\text { - My wife was never given a card. Why is that? I think everyone should have } \\
\text { one. }\end{array}$ \\
\hline
\end{tabular}

.506). A multivariate analysis of variance was conducted to assess differences in the multiple responses before and after the test among those who did and did not use the card. This analysis supported the hypothesis (Wilks $\Lambda=0.678$; F (4, $37)=4.39 ; P=.005)$. Follow-up univariate analyses revealed that the patients who did not use the card scored higher in the perceived patient responsibility domain in the phase before the intervention $(P=.011)$. However, those who used the card scored higher in this domain after intervention $(P=.022)$.

Qualitative analysis of the patients' responses showed 4 major themes at follow-up among those using the medication card (see Table 2). These themes indicated that the medication card was useful not only as a reference to the patient, their physicians, and their families, but that it was also helpful as an information source across health care settings. The large majority of patients using the card indicated that the card was easy to use and carry. However, the 2 most common barriers among those using the card were that the card was too large to fit in the wallet ( 2 patients) and it did not have enough room to list all the medications (2 patients). Of interest, Table 3 shows that, among the 41 patients contacted for the survey after the intervention who were not using the card, 16 indicated future interest in using the card and 3 were already using their own.

\section{Discussion}

This pilot study indicates that a significant percentage of patients were willing to use a self-maintained medication list card. This is concordant with a 2004 Harris Poll where $42 \%$ of the 2242 adults participating in this online survey kept some type of personal or family health record. ${ }^{25}$ There was significant interest in using the card even among those not using the card at follow-up (see Table 3). In fact, almost half of those who were not using the provided card (19 of 41) were either interested in using it in the future or were using one of their own. Several of these patients indicated that they did not fully understand the use of the medication list card when it was first distributed to them and that this hampered their initial willingness to use the card.

These findings also suggest that those who used the card had an improved sense of knowledge about their medical problems and medications. The active involvement in maintaining such a card seemed to enhance their sense of responsibility and may have helped them take a more active role in their medical care.

Table 3. Responses of Patients Who Reported Not Using the Medication List Card*

\begin{tabular}{lr}
\hline Response & $\mathrm{n}$ \\
\hline Wanted another copy of the card sent to them & 12 \\
Reported planning to use the card in the future & 1 \\
$\begin{array}{l}\text { Reported thinking that the card is a "good } \\
\text { idea" or "useful" }\end{array}$ & 3 \\
$\begin{array}{l}\text { Reported using their own wallet medication list } \\
\text { card }\end{array}$ & 3 \\
\hline
\end{tabular}

*Forty-one of 66 patients who were contacted reported not using the medication list card. Of these, 16 indicated interest in the card and 3 were using their own. 
Another consideration is that the use of the medication list card may have been a marker of the health literacy of the participants. In this case, the greater gain in the patient knowledge domain of the PMS may have been at least in part because of the association between literacy and health knowledge. $^{22,23}$ The distribution of a medication list card may serve the alternate purpose of helping providers identify those patients who have inadequate health literacy through further sensitive questioning of those who do not use the card.

It is also possible that those using the medication list card asked additional questions regarding the medications prescribed to them, which may have increased their understanding and overall knowledge of their medical problems. Such a dialogue is essential in improving patient-provider communication and enhancing patient understanding of their medical problems and the medications used to treat them. ${ }^{26}$ This possibility was not evaluated by this study and it would be interesting to assess this in future investigations.

Of note, the respondents who did not use the card scored higher in the patient responsibility domain of the PMS in the preintervention phase. However, in the postintervention interview, it was the participants who used the card who scored higher in this domain. This lends further support to the hypothesis that the use of the card increased a sense of patient responsibility, rather than the possibility that those who already had a greater sense of responsibility used the card.

Research indicates that the promise of electronic records in maintaining correct medication lists is limited without full patient involvement. ${ }^{12,15}$ Given that $52.5 \%$ of the respondents in this study indicated that they obtain their prescriptions from more than one health care provider, it is important that patients are involved in updating each clinician regarding the medications prescribed by others, as well as the over-the-counter medications they take. This study was focused on ascertaining the patients' acceptance of using medication list cards and the effect of such use on their perceptions. Future studies are needed to determine whether this can also improve medication adherence and reconciliation, which are key components in treatment efficacy and patient safety.

Although the ideal is the development of integrated health information systems with secure patient portals that allow easy access to medical in- formation including test results, diagnoses, and medications, ${ }^{27}$ this paper tool may serve an intermediary role while a national electronic infrastructure is being developed and access is broadened to more patients.

\section{Limitations}

As a pilot study using a convenience sample with a limited number of patients, these findings need to be confirmed by larger studies conducted in other practice settings. In addition, the PMS was developed for this study and should be validated in other patient settings to determine its broader validity. The use of a phone interview for the postintervention questionnaire also limited the ability to obtain contact with the full sample (the investigators were able to contact only 66 of 99 patients). In addition, the majority of those willing to complete the full postintervention survey were using the card (25 of 42), which may have skewed the results on the PMS after intervention. The follow-up phone interviews also occurred over a prolonged period (4 to 11 months) because of the limited time resources of the investigators, and this may have also affected the results.

However, this small study offers intriguing findings that indicate another avenue of research in improving patient-physician communication, increasing involvement of patients in their medical care, and potential patient safety enhancements in medication reconciliation.

\section{Future Directions}

Because of the limited resources available for conducting this study, it was restricted in scope. It would be ideal to not only provide the medication list card, but to reinforce its use at every office visit by each member of the health care team. For example, the receptionist could remind the patient to bring their card (in addition to any "brown bag" of medications to help confirm the accuracy of this list), the nurse/physician team could review and update the list with the patient during each visit, and the inpatient team could update the list before discharge. Although many practices are now providing patients with after-visit summaries including medications via printouts from the electronic medical record, and hospitals provide printouts of discharge medications, the wallet-sized nature of this card may improve the likelihood that patients will bring this list to all health care settings. 
One of the barriers identified in expanding the use of personal medication lists is the lack of reinforcement by health care providers to start and maintain such lists. ${ }^{28}$ It also would be interesting to determine whether there is improved use of the card by patients if the providers themselves are also instructed and supported to maintain their own cards.

Another avenue of research would be to explore the impact of the use of the medication list card on patient-provider communication. It would be helpful to elucidate if the use of the card encourages patients to more regularly question their providers regarding their medical problems and the medications used to treat them. This communication and patient education is important in improving patient adherence to treatment recommendations and thus has great potential to enhance outcomes. ${ }^{29}$

In addition, it would be interesting to look at the use of the medication list card as a way to help determine the health literacy of patients. With sensitive questioning, a provider could broach this issue among those who do not use the card or clearly have problems using the card to determine whether this is the underlying problem. In that case, other medication lists with a more pictorial format could be used to determine whether they enhance patient understanding of the use of the medications and subsequent adherence to recommended treatment plans.

Future studies could explore whether such integrated use of a wallet medication list card truly improves the accuracy of the medication list (by comparison with medications during home visits or via the "brown bag" method), the adherence to treatment, and patient-provider interactions. In an age where the partnership model of the physician patient relationship is espoused, such a low technology tool may enhance communication and patient care.

The authors thank Robin O. Winter, MD, MMM, Director, JFK Family Medicine Residency Program, Edison, New Jersey.

\section{References}

1. The Joint Commission. 2008 National patient safety goals. Ambulatory care. Available from: http://www. jointcommission.org/NR/rdonlyres/A391E808-AF104C5E-873D-CB185E2009F0/0/08_AHC_NPSGs_ Master.pdf. Accessed May 15, 2008.

2. The Joint Commission. "What did the doctor say?:" improving health literacy to protect patient safety. 2007. Available from: http://www.jointcommission. org/NR/rdonlyres/D5248B2E-E7E6-4121-8874-
99C7B4888301/0/improving_health_literacy.pdf. Accessed September 9, 2009.

3. Andersen SE, Pedersen AB, Bach KF. Medication history on internal medicine wards: assessment of extra information collected from second drug interviews and GP lists. Pharmacoepidemiol Drug Saf 2003;12:491-8.

4. Gleason KM, Groszek J, Sullivan C, Rooney D, Barnard C, Noskin GA. Reconciliation of discrepancies in medication histories and admission orders of newly hospitalized patients. Am J Health Syst Pharm 2004;61:1689-94.

5. Beers MH, Munekata M, Storrie M. The accuracy of medication histories in the hospital medical records of elderly persons. J Am Geriatr Soc 1990; 38:1183-7.

6. Lau HS, Florax C, Porsius AJ, de Boer A. The completeness of medication histories in hospital medical records of patients admitted to general internal medicine wards. Br J Clin Pharmacol 2000;49: 597-603.

7. Bedell SE, Jabbour S, Goldberg R, et al. Discrepancies in the use of medications: Their extent and predictors in outpatient practice. Arch Intern Med 2000;160:2129-34.

8. Yang JC, Tomlinson G, Naglie G. Medication lists for elderly patients. J Gen Intern Med 2001;16: 112-5.

9. Kaboli PJ, McClimon BJ, Hoth AB, Barnett MJ. Assessing the accuaracy of computerized medication histories. Am J Managed Care 2004;10:872-7.

10. Bikowski RM, Ripsin CM, Lorraine VL. Physicianpatient congruence regarding medication regimens. J Am Geriatr Soc 2001;49:1353-7.

11. Varkey $\mathrm{P}$, Cunningham J, Bisping S. Improving medication reconciliation in the outpatient setting. Jt Comm J Qual Patient Saf 2007;33:286-92.

12. Stephens M, Fox B, Kukulka G, Bellamy J. Medication, allergy, and adverse drug event discrepancies in ambulatory care. Fam Med 2008;40:107-10.

13. Biondich PG, Grannis SJ. The Indiana network for patient care: an integrated clinical information system informed by over thirty years of experience. J Public Health Manag Pract 2004;(Suppl):S81-6.

14. Hillestad R, Bigelow J, Bower A, et al. Can electronic medical record systems transform health care? Potential health benefits, savings and costs. Health Aff 2005;24:1103-17.

15. Nassaralla CL, Naessens JM, Chaudhry R, Hansen MA, Scheitel SM. Implementation of a medication reconciliation process in an ambultaory internal medicine clinic. Qual Saf Health Care 2007;16:90-4.

16. Gandhi TK, Weingart SN, Seger AC, et al. Outpatient prescribing errors and the impact of computerized prescribing. J Gen Intern Med 2005;20:837-41.

17. Peng CC, Glassman PA, Trilli LE, Hayes-Hunter J, Good CB. Incidence and severity of potential drugdietary supplement interactions in primary care pa- 
tients: an exploratory study of 2 outpatient practices. Arch Intern Med 2004;164:630-6.

18. Kennedy J, Wang C, Wu C. Patient disclosure about herb and supplement use among adults in the US. Evid Based Complement Alternat Med 2008;5:451-6.

19. Endsley S, Kibbe DC, Linares A, Colorafi K. An introduction to personal health records. Fam Pract Manag 2006;13:57-62.

20. Smith S, Barefield A. Patients meet technology: the newest in patient-centered initiatives. Health Care Manag (Frederick) 2007;26:354-62.

21. Kupchunas W. Personal health record: new opportunity for patient education. Orthop Nurs 2007;26:185-91.

22. Health literacy: report of the Council on Scientific Affairs. Ad Hoc Committee on Health Literacy for the Council on Scientific Affairs, American Medical Association. JAMA 1999;281:552-7.

23. Safeer RS, Keenan J. Health literacy: the gap between physicians and patients. Am Fam Physician 2005;72:463-8.
24. Orcher L. Conducting research: social and behavioral science methods. Glendale, CA: Pyrczak Publishing; 2005.

25. Harris Interactive, Health Care News. Two in five adults keep personal or family health records and almost everybody thinks this is a good idea: electronic health records likely to grow rapidly. Available from: http://www.harrisinteractive.com/news/newsletters/ healthnews/HI_HealthCareNews2004Vol4_Iss 13 . pdf. Accessed April 25, 2008.

26. Lussier M, Richard C. Medication list: enhancing patients' knowledge and adherence. Can Fam Physician 2007;53:233-6.

27. Tang PC, Lansky D. The missing link: bridging the patient-provider health information gap. Health Aff 2005;24:1290-5.

28. Traynor K. Personal medication record campaigns get underway. Am J Health Syst Pharm 2007;64:1781-4.

29. Osterberg L, Blaschke T. Adherence to medication. N Engl J Med 2005;353:487-97.

\section{Appendix 1. Patient Medication Scale.}

Please circle the answer that most closely describes the way you feel about the following statements based on the scale below.

Strongly Agree
Agree
Neutral
Disagree Strongly Disagree

1. I know the names of all the medications that I am taking now. (PK)

2. I don't really know the medical problems that I am taking my medications for. (PK)

3. I am not sure about the dosages of the medications I am taking. (PK)

4. I usually remember to tell my doctor what over the counter and herbal medications that I am taking. (PR)

5. I feel that I take an active part in my medical care. (PR)

6. I feel that my doctor should be the only one responsible for organizing and maintaining my medical information. (PhR)

7. My doctor usually doesn't ask me what medications I am currently taking. (PhR)

8. I feel that I have a responsibility in keeping an accurate record of my medical information. (PR)

9. My doctor usually asks me what nonprescription and herbal medicines I am taking. (PhR)

Domains: Patient Knowledge (PK), Patient Responsibility (PR), Physician Responsibility (PhR) 
Appendix 2. Postintervention phone interview script.

\section{Patient Post Intervention Phone Interview}

1. Name of Participant

2. Name of Interviewer

"Hello, my name is and I am calling you from the JFK Family Medicine Center.

About 4-6 months ago, you agreed to participate in a study involving the use of self maintained medication list cards. This involves a phone interview that will take approximately 10 to 15 minutes of your time. Can I proceed with the interview now?"
Yes
No

If no:

"When can I call you back to go over the interview with you?"

Date to call back

Time AM PM

If the patient declines continued participation in the study:

"Why did you decide to stop participating in this study?"

If yes:

3. Date of Contact

4. Are you using the wallet medication list card handed out to you at JFK Family Medicine Center 46 months ago?

Yes

No

5. What was it like to us this medication card?

6. Was there anything about this medication card that made it easy to use?

7. Was there anything about this medication card that made it hard to use? 


\section{Appendix 2. Continued}

8. Can you tell me about a time when you felt that this medication card was useful?

9. Do you have any suggestions on how to make the use of this card easier?

10. Do you have any suggestions on other ways to help us keep an up to date list of all your medications?

"Now I am going to ask you to answer some other questions based on a scale. Please answer the question by using the number that most closely describes the way you feel about the following statements based on the scale I am going to describe to you now.

This scale ranges from 1 to 5 with

1 meaning strongly agree,

2 meaning agree

3 meaning neither agree nor disagree (neutral)

4 meaning disagree,

and $\mathbf{5}$ meaning strongly disagree.

Patient Medication Scale is then readministered (see Appendix 1). 